-

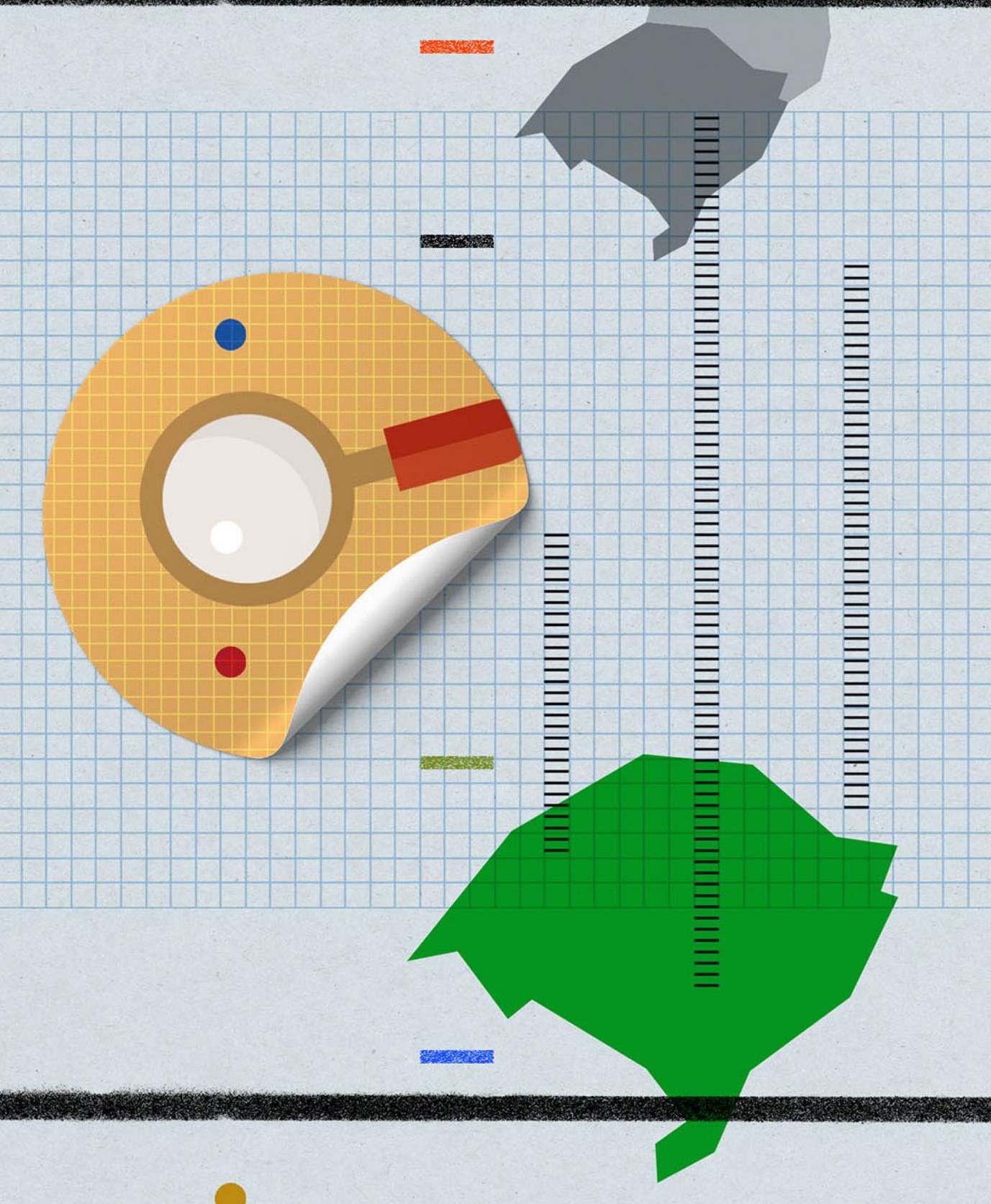




\title{
Políticas públicas para promoção de exportações - análise de sua disponibilidade para as micro e pequenas empresas no Rio Grande do Sul
}

\section{Public policies for export promotion - analysis of its availability for micro and small companies in Rio Grande do Sul}

\author{
Queila Cordeiro* | Moema Pereira Nunes** \\ http://dx.doi.org/10.51861/ded.dmvu.2.009 \\ Recebido em 19 de maio de 2020. Aceito em 15 de maio de 2021.
}

Resumo

As micro e pequenas empresas representam uma parcela importante na economia brasileira. Além de atuarem no mercado nacional, elas também exercem atividades de mercado internacional. Entretanto, essa participação não possui números expressivos. Neste contexto, este trabalho busca apresentar quais as políticas públicas de promoção existentes para apoiar as exportações de micro e pequenas empresas localizadas no Rio Grande do Sul, além de investigar as ações de qualificação de pessoas e discutir os resultados decorrentes destas políticas. O estudo compreendeu uma revisão bibliográfica complementada com uma pesquisa de campo, a qual contou com a realização de entrevistas para a coleta de dados primários. Constatou-se a oferta de programas nos âmbitos federal e estadual às empresas gaúchas, não apenas para a promoção comercial, mas também para a qualificação de pessoas. A análise dos impactos destas políticas é limitada devido à falta de indicadores de acompanhamento das empresas que sejam publicamente divulgados.

Palavras-chave: Políticas Públicas; Promoção à exportação; Micro e Pequenas Empresas; Rio Grande do Sul.

\begin{abstract}
Micro and small companies represent an important part of the Brazilian economy. In addition to operating in the domestic market, they also engage in international market activities. However, this participation does not have significant numbers. In this context, this work seeks to present the public promotion policies that exist to support exports by micro and small companies located in Rio Grande do Sul, in addition to investigating the qualification of people and discussing the impacts generated by these policies. The study comprised a bibliographic review complemented with a field research, which included conducting interviews for the collection of primary data. It was found that programs at the federal and state levels were offered to companies in the state of Rio Grande do Sul, not only for commercial promotion, but also for the qualification of people. The analysis of the impacts of these policies is limited due to the lack of indicators for monitoring companies that are publicly disclosed.
\end{abstract}

Keywords: Public Policies; Export promotion; Micro and Small Companies; Rio Grande do Sul.

\footnotetext{
* Queila Cordeiro

Bacharel em Administração de Empresas, Universidade Feevale. ERS-239, 2755, Bairro Vila Nova, 93525-075, Novo Hamburgo, RS, Brasil. Orcid: https://orcid.org/0000-0003-4928-2099. E-mail: queilacordeiroqc@hotmail.com

** Moema Pereira Nunes

Professora da Universidade Feevale (Brasil) e da Otto-von-Guericke Universität Magdeburg (Alemanha). ERS-239, 2755, Bairro Vila Nova, 93525-075, Novo Hamburgo, RS, Brasil. Orcid: https://orcid.org/0000-0002-9729-9074. E-mail:moemanunes@hotmail.com
} 


\section{INTRODUÇÃO}

As oportunidades de expansão do mercado de atuação das empresas para outros países têm atraído cada vez mais gestores para o ambiente global. No ano de 2019, o Brasil obteve um superávit de US\$ 46 bilhóes, representando um desempenho inferior ao ano de 2018. Observando apenas as exportaçóes, houve uma queda de 7,5\% em comparação à média do ano de 2018. Apesar disso, a participação no mercado internacional não pode ser ignorada pelas empresas brasileiras e novas oportunidades precisam ser desenvolvidas continuamente.

Um perfil de empresa que vem destacando-se nas exportaçôes brasileiras são as micro e pequenas empresas (MPEs). Segundo estatísticas da Secretaria de Comércio Exterior do Ministério da Economia, as MPEs possuem uma parcela pequena no percentual de volume das exportaçóes brasileiras. No entanto, o número das MPEs que operam no comércio internacional está crescendo. No ano de 2016 representavam 49,6\% dos exportadores brasileiros (MINISTÉRIO DA ECONOMIA, 2017).

De acordo com dados do Serviço Brasileiro de Apoio às Micro e Pequenas Empresas (Sebrae) (SEBRAE, 2017), no Brasil, MPEs representam números significantes para a economia. As MPEs configuram 98,5\% dos empreendimentos do país, e ainda respondem por mais de um quarto do Produto Interno Bruto (PIB), cerca de $27 \%$ do PIB, dados referentes ao ano de 2017. Atualmente, existem duas definiçôes para classificar o que são as micro e pequenas empresas. A definição mais comum é a que está na Lei Geral para Micro e Pequenas Empresas, de 2006, que classifica a empresa pelo seu faturamento anual. Outra definição para classificação é feita pelo Sebrae, que as segmenta por meio do número de funcionários que a empresa emprega (BUENO, 2017).

Ao passo que muitas MPEs brasileiras buscam oportunidades em mercados externos, torna-se mais evidente que realizar negócios com outros países requer preparação. Por isso, entidades como a Agência Brasileira de Promoção e Investimentos (Apex-Brasil) ofertam programas de capacitação e fortalecimento para a exportação, com o intuito de contribuir com as empresas para que elas entendam melhor o processo de exportação, conseguindo atingir o objetivo de desenvolvimento e competitividade global (APEX-BRASIL, 2018). Além de programas de abrangência nacional, os governos estaduais também podem ofertar programas para apoiar as exportaçóes das MPEs, como ocorre no Rio Grande do Sul.

Perante esse contexto, a problemática deste trabalho consiste em investigar: Quais políticas públicas são ofertadas para o apoio à promoção das exportaçóes das MPEs no Rio Grande do Sul? Desse modo, esta pesquisa 
tem como objetivos (i) apresentar as políticas públicas de promoção de exportações oferecidas a nível nacional e estadual para as MPEs localizadas no Rio Grande do Sul; (ii) investigar as ações de promoçốes comerciais de qualificação de pessoas para prática de exportação; e (iii) revelar os resultados percebidos como consequência das políticas públicas para promoção das exportações das MPEs gaúchas.

$\mathrm{O}$ artigo apresenta uma contribuição prática e reflexiva sobre como as políticas públicas contribuem e influenciam as exportaçóes das MPEs gaúchas. Por conta das limitações de conhecimento dos programas ofertados pelo poder público, micro e pequenos empresários ficam limitados ao mercado local, sem prospectar mercados externos potenciais. Desse modo, entende-se que os resultados desta pesquisa, além da contribuição teórica, podem servir de orientação para MPEs, associações, entidades ou cooperativas que buscam entrar no mercado externo por meio de exportaçóes.

\section{AS MPES BRASILEIRAS E SUA PARTICIPAÇÃO NO COMÉRCIO EXTERIOR}

As MPEs aparecem como atores principais no cenário econômico do Brasil. Mesmo não possuindo uma grande representatividade no comércio exterior, elas são responsáveis por grande parte do número de empresas do país, contribuindo para geração de empregos e constituindo uma parte significativa do PIB brasileiro. No que se refere à importância na atividade econômica do país, pode-se destacar, de acordo com o Sebrae (2017), que o número de MPEs cresceu 27,5\% entre os anos de 2005 e 2015, chegando a cerca de 6,8 milhões de MPEs no Brasil no período. Essas empresas geram aproximadamente 54\% dos empregos formais do país. As MPEs representam 99\% dos estabelecimentos existentes no Brasil.

As micro e pequenas empresas apresentam grande importância no funcionamento da economia brasileira em virtude da capacidade de absorção de mão-de-obra, da geração de renda, do número de estabelecimentos e do potencial de abertura de novos negócios (CONFEDERAÇÃO NACIONAL DO COMÉRCIO, 2017).

Outra consideração a respeito das MPEs é que:

[...] o segmento mostra resiliência e importância na conformação do mercado de trabalho e na estrutura produtiva do Brasil e é estratégico para as políticas de retomada do crescimento econômico, aumento de produtividade e distribuição de renda (SEBRAE, 2017, p. 33). 
A participação das MPEs nas exportações brasileiras tem se ampliado nos últimos anos. De acordo com o Ministério da Economia (2017), o número de MPEs que atuam no comércio internacional obteve um crescimento de $16 \%$ em 2016, passando de 10.920 para 12.671 , representando $49,6 \%$ dos exportadores brasileiros.

Pode-se observar na Figura 1 que houve um aumento em valores totais de exportação nos últimos vinte anos. No ano de 2011, os valores aumentaram cerca de cinco vezes se comparados a 1997. De 2012 a 2017, os valores exportados apresentaram queda quando comparados ao ano de 2011, quando ocorreu o maior valor de exportaçôes.

Figura 1 - Valores das exportações das MPEs no período de 1997 a 2017

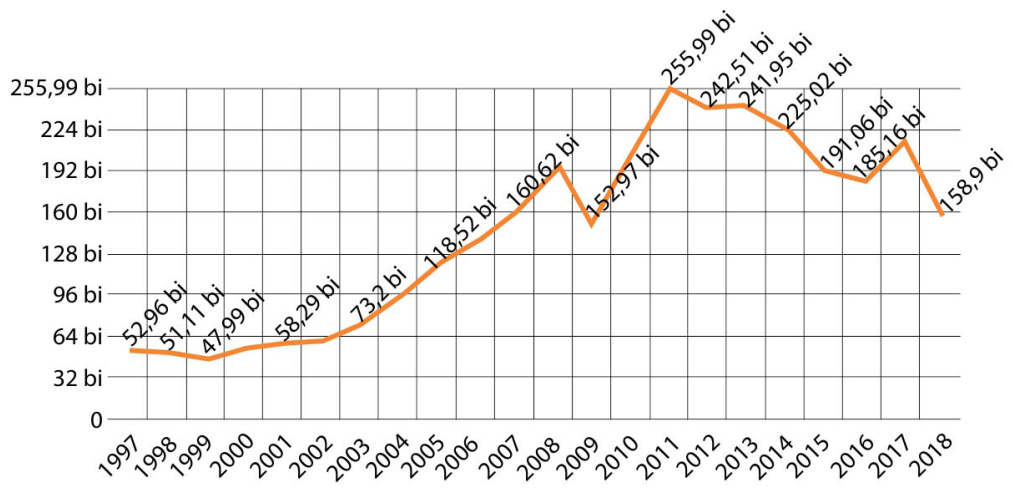

Fonte: Sebrae (2018)

Ao analisar a participação das MPEs nas exportaçóes brasileiras no ano de 2018, os pequenos negócios representaram 40,8\% das empresas exportadoras no Brasil. No período entre os anos de 2009 a 2017, o número de MPEs exportadoras teve um aumento recorde, alcançando uma alta acumulada de $44 \%$ nesses últimos seis anos. Em relação ao número de MPEs exportadoras, em 2017, o Brasil contou com um total de 8.863, sendo 3.856 microempresas e 5.007 pequenas empresas. Dentre os principais destinos das exportações das MPEs estão o Mercosul, Estados Unidos, Canadá, União Europeia e nações que integram a Associação Latino-Americana de Integração (ALADI) (GONDIM, 2018). Os percentuais das exportaçóes de acordo com os destinos são apresentados na Figura 2. 
Figura 2 - Destinos das exportações das micro e pequenas empresas em 2016

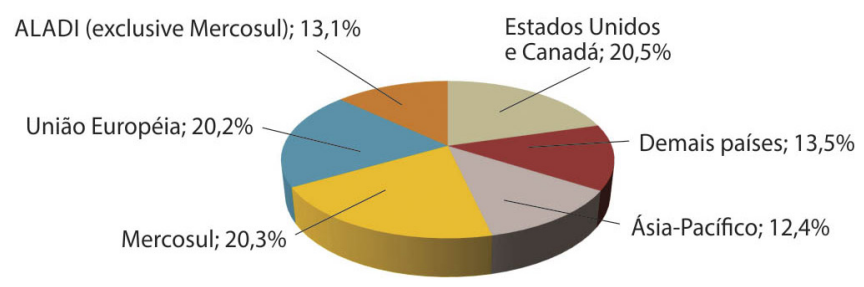

Fonte: Sebrae (2017)

Outro ponto importante a ser analisado nas exportações das MPEs é o ramo de atividade, sendo a predominância no ramo comercial. Cerca de $45 \%$ do número de empresas e do valor exportado em 2017 referem-se a empresas do comércio varejista e de atacado. Nas pequenas empresas, também ocorre o predomínio dos setores do comércio varejista e de atacado; nesse caso, correspondem a 34,3\% das exportações (SEBRAE, 2018).

A pauta de produtos exportados, por sua vez, é bem diversificada. Os cinco principais itens exportados pelas MPEs correspondem somente a $13,7 \%$ das vendas. Destaque para os produtos de vestuário para mulheres e meninas, calçados, suas partes e componentes, e pedras preciosas ou semipreciosas. A diversificação é constatada também ao se identificar que os cinco principais itens exportados representam 16,2\% das vendas (SEBRAE, 2018).

Conforme o Sebrae (2017), a tendência é que as exportaçốes realizadas pelas MPEs cresçam em decorrência dos avanços obtidos para desburocratizar o processo de exportação para o pequeno exportador. Além disso, existem diversas opçóes de incentivos, juntamente com programas que proporcionam simplificação do processo de exportação, os quais serão apresentados e analisados após o método de pesquisa.

\section{MÉTODO DE PESQUISA}

Para o desenvolvimento deste estudo foi realizada uma pesquisa aplicada de natureza descritiva. Gil (2002) salienta que a pesquisa descritiva busca descobrir a existência e a relação de associaçóes entre determinadas variáveis, neste caso, a compreensão dos programas de apoio à exportação pelas MPEs gaúchas.

Em relação aos procedimentos técnicos, optou-se pela pesquisa bibliográfica e pela pesquisa de campo. Fachin (2006) descreve a pesquisa bibliográfica como a base para as demais pesquisas, sendo sua finalidade proporcionar ao leitor o conhecimento sobre determinado assunto. Quanto à pesquisa 
de campo ou estudo de campo, ela procura resultados caracterizados pelo aprofundamento das questóes propostas. Prodanov e Freitas (2013) definem a pesquisa de campo como aquela que é utilizada com o objetivo de conseguir informaçóes para um problema que se busca uma resposta; consiste em observar fatos e coletar dados referentes a eles, que sejam relevantes para analisá-los. Do ponto de vista da forma de abordagem do problema, trata-se de uma pesquisa qualitativa.

A unidade de análise deste trabalho envolveu as entidades e os programas de apoio à exportação disponibilizados às MPEs no estado do Rio Grande do Sul. Para que fosse possível complementar a pesquisa bibliográfica foram realizadas quatro entrevistas com especialistas do setor de comércio exterior com conhecimento ou com atuação em programas de promoção à exportação, os quais foram selecionados por acessibilidade e conveniência. Durante estas entrevistas percebeu-se a necessidade de entrevistar o gestor de uma MPE que houvesse participado dos programas de apoio à exportação. Com o apoio dos entrevistados foram identificadas oito MPEs exportadoras com perfil adequado ao objetivo de pesquisa. Foi realizado o contato via e-mail e ligações telefônicas com estas potenciais empresas, no entanto, somente uma delas se dispôs a participar. O perfil dos entrevistados é apresentado a seguir:

a) Entrevistado 1. Coordenador da divisão de inteligência de mercado na Secretaria de Desenvolvimento Econômico do estado do Rio Grande do Sul. Doutor em Administração.

b) Entrevistado 2. Profissional com 30 anos de experiência no Governo do Estado do Rio Grande do Sul, sendo coordenador do programa Sala do Exportador. Por duas vezes ocupou o cargo de diretor de promoção comercial e assuntos internacionais no governo estadual. Especialista em Gestão de Projetos.

c) Entrevistado 3. Atuou como coordenador do Peiex em núcleo operacional no Rio Grande do Sul. Bacharel em Economia.

d) Entrevistado 4. Fundador e diretor técnico de uma microempresa. Bacharel em Engenharia.

e) Entrevistado 5. Gerente regional no escritório gaúcho de uma entidade de classe. Doutor em Engenharia de Produção.

Todas as entrevistas foram realizadas no ano de 2019 e gravadas mediante autorização. Os entrevistados autorizaram o uso dos seus nomes, mas visando a impessoalidade das informaçóes, optou-se pela não divulgação dos mesmos.

$\mathrm{Na}$ sequência foi realizada a análise e interpretação dos dados coletados nas entrevistas em conjunto com os dados coletados na pesquisa bibliográfica. 
Segundo Marconi e Lakatos (2010), a análise e a interpretação dos dados estão relacionadas; no entanto, são processos distintos. A análise é a tentativa de explicar as relaçóes existentes entre o estudo e outros fatores. Já a interpretação procura dar um significado às respostas, fazendo uma relação entre os objetivos propostos e o material apresentado. A apresentação dos resultados inicia com a investigação das políticas públicas de promoção às exportaçóes disponíveis às MPEs localizadas no Rio Grande do Sul.

\section{POLÍTICAS PÚBLICAS DE PROMOÇÃO ÀS EXPORTAÇÕES DIS- PONÍVEIS ÀS MPES LOCALIZADAS NO RIO GRANDE DO SUL}

O mercado externo surge como uma oportunidade de crescimento e diversificação para as MPEs, mas é necessário conhecer esse mercado, assim como todas as atividades e circunstâncias que o envolvem. Com o objetivo de contribuir para que as MPEs conheçam o mercado internacional, há políticas e programas de incentivos à exportação direcionadas a programas de qualificação e extensão empresarial, programas de incentivos e promoçôes produtivas, além de programas de competitividade.

Esta análise inicia com a investigação da oferta de açóes pelo governo do Estado do Rio Grande do Sul. O Programa Exporta-RS foi criado em 2016 e visa ampliar e solidificar a participação das MPEs gaúchas no mercado internacional, ofertando atendimentos personalizados para os empreendedores identificarem suas possibilidades de exportação (SECRETARIA DO DESENVOLVIMENTO ECÔNOMICO E TURISMO, 2019).

É um programa que trabalha só com promoção de exportações e só com micro, pequenas e médias empresas e só do Rio Grande do Sul, ou seja, seguindo essas três exigências nós tentamos qualificar tanto a capacitação dos agentes da empresa para poder buscar informaçôes ou pra usar informaçôes que nós geramos, quanto para gerar informaçôes úteis, lista de exportadores, melhores mercados, tendências, para que essas pessoas possam eventualmente dar o próximo passo dentro de suas empresas (ENTREVISTADO 1).

O Programa Exporta - RS atua em “duas frentes”, conforme apontado pelo Entrevistado 1. A primeira contribuição do programa é a busca de informaçóes essenciais para prospecção de mercados no exterior para as empresas. A segunda é a oferta de qualificações para os gestores das empresas. A busca por novos mercados é um estudo realizado pela equipe do Exporta - RS. Segundo o Entrevistado 2, trata-se de um estudo bem completo, que detecta quais os mercados que consomem o produto que a empresa oferece e quais as certificações necessárias para ingressar naquele mercado. 
Outra proposta do programa é a organização e promoção de seminários de qualificação em conjunto com parceiros como os Correios, o Sebrae, a Fecomércio, Fiergs, Banco do Brasil, entre outros. Esses seminários são chamados de Caminhos da Exportação, e reúnem as empresas para falar sobre diferentes aspectos que envolvem o processo de exportação (ENTREVISTADO 1). O Entrevistado 1 destaca que o seminário aborda "[...] a relevância da exportação, como dar os primeiros passos, vai apresentar todos os programas que nós e os parceiros temos à disposição dessas micro e pequenas empresas”. Complementando as atribuiçốes do Exporta - RS, o Entrevistado 2 menciona que o programa realiza eventos em que é explicado aos gestores das empresas como participar de missóes internacionais com rodadas de negócios para conhecer o mercado externo.

Paralelamente, o Governo do Estado do Rio Grande do Sul também tem um programa voltado à inserção das empresas gaúchas em feiras internacionais. O Programa de Apoio à Participação de Empresas Gaúchas em Feiras Internacionais foi mencionado pelos Entrevistados 1 e 2. A feira não precisa ser necessariamente fora do país, mas, sim, feiras internacionais que ocorram aqui no Brasil ou em outros países com a participação de expositores internacionais. As feiras que as empresas irão participar são selecionadas a partir de suas demandas (ENTREVISTADO 2).

Todos os anos existe uma montagem de calendário conforme o interesse das empresas. Como é que a gente descobre o interesse das empresas? Do meio do ano para o fim a gente começa a sondar as entidades de classe, as associaçóes dos setores econômicos, as próprias empresas com quem nós já temos contato e eles vão mandando demanda (ENTREVISTADO 1).

O calendário de feiras é organizado a partir do orçamento que o Estado disponibiliza para este programa, ou seja, o Estado incentiva financeiramente a participação das empresas nas feiras pagando de 80 a 90\% dos custos com estandes. O Estado aluga um estande coletivo e o separa entre as empresas selecionadas. Assim, conforme explicaram os Entrevistados 1 e 2, cada empresa tem seu espaço particular, reduzindo os custos de exposição nestes eventos.

Dando sequência às políticas de promoção à exportação ofertadas a nível estadual, o Entrevistado 1 destacou o Programa de Harmonização do Desenvolvimento Industrial do Rio Grande do Sul (Fundopem/RS). De acordo com a Secretaria de Desenvolvimento Econômico e Turismo (2019a), o Fundopem/RS é um incentivo financeiro que o Governo do Estado concede às empresas que realizam projetos de investimentos no próprio Estado, os quais resultam na implantação ou expansão de unidades industriais. As empresas 
incentivadas apropriam-se do incentivo por meio de financiamento de um determinado percentual do Imposto Sobre Circulação de Mercadorias e Serviços (ICMS).

Quando questionados sobre os programas a nível de Governo Federal, os Entrevistados 1 e 3 destacaram os projetos da Apex Brasil. A APEX Brasil promove os serviços e produtos brasileiros no mercado externo, buscando atrair investimentos estrangeiros para setores estratégicos da economia brasileira A Agência atua de diversas formas para promover a competividade das empresas brasileiras no processo de internacionalização. Dentre os serviços oferecidos, estão estudos e análises que orientam as empresas sobre as melhores oportunidades de negócios internacionais, os programas de qualificação profissional para promover a cultura exportadora nas empresas, serviços de orientação na definição de estratégias para inserção internacional, ações que facilitam o acesso das empresas brasileiras ao mercado internacional, diversificando os destinos das exportações e melhorando a visão internacional sobre as empresas, serviços e produtos brasileiros, além da realização de ações de atração de investimentos com o objetivo de melhorar a imagem do Brasil como um mercado atrativo para investimentos de capital estrangeiro. Essas ações de atração de investimentos buscam induzir a transferência de tecnologias inovadoras para empresas brasileiras (APEX BRASIL, 2018).

Dentre estas açôes destaca-se o Programa de Qualificação para Exportação (Peiex) que é um instrumento de caráter estruturante aos setores e de reforço da base exportadora do Brasil. Para as empresas que estão iniciando no comércio exterior, o Peiex busca estimular a competividade, qualificando e ampliando os mercados. Suas ações ocorrem em locais de concentração empresarial e vão desde atuar em processos internos, mediante recursos disponíveis nas empresas, até processos externos, como acesso a mercados. O Peiex é representado por Núcleos Operacionais que são unidades instaladas nos estados brasileiros responsáveis pelo atendimento às empresas. O programa oferece consultoria gratuita para as empresas que necessitam de aprimoramento, por meio de visitas da equipe técnica e encontros de capacitação para melhoria de gestão de processos e produtos (APEX BRASIL, 2018).

Com base na assessoria e no diagnóstico realizados pela equipe executora do projeto, é possível ampliar a competitividade das empresas por meio da melhoria nas áreas de estratégia organizacional, vendas, marketing, custos, entre outras. A qualificação das empresas ocorre a partir da participação em seminários sobre a cultura exportadora, rodadas de negócio e missões internacionais (INVEST \& EXPORT BRASIL, 2018).

O Entrevistado 1 definiu o programa como uma especialização para que os empresários aprendam o passo a passo do comércio exterior, preparando a 
sua empresa para começar a exportar. O Entrevistado 3 destacou que o objetivo do Peiex é "capacitar principalmente micro, pequenas e médias empresas para serem inseridas no mercado exportador”. O Entrevistado 5 complementa afirmando que as empresas encaminhadas ao Peiex têm a oportunidade de serem capacitadas para trilhar um caminho com maior naturalidade, ou seja, a empresa busca amadurecer seu conhecimento sobre exportação, por meio de rodadas de negócio e de missóes internacionais, ampliando gradativamente suas atividades para o mercado externo.

O Entrevistado 3 explica que algumas empresas que almejam o mercado externo procuram os núcleos operacionais do Peiex; outras, são procuradas mediante prospecções realizadas pelos núcleos. Assim, após a visita de um técnico explicando como o programa funciona, é realizado um diagnóstico que identifica quais as demandas da empresa. A partir deste diagnóstico são hierarquizadas as demandas, sendo direcionadas as soluçốes mais apropriadas às dificuldades de cada empresa. O empresário, a partir das suas necessidades, participa de cursos na área de recursos humanos, de finanças, marketing internacional, entre outros, e implementa as melhorias na sua empresa com o acompanhamento do técnico.

Além disso, cabe destacar os projetos setoriais desenvolvidos por outras entidades que também sustentam a inserção das empresas no mercado internacional. As entidades públicas e privadas que são parceiras destes programas têm por objetivo fortalecer a cultura exportadora; além disso, contribuem para a participação contínua das empresas no mercado externo (APRENDENDO A EXPORTAR, 2018a). As parcerias entre as entidades e a Apex Brasil proporcionam cursos de qualificação e visitas a outras empresas para aquisição de conhecimento, assim como subsídios para a exportação, conforme destacou o Entrevistado 5.

Considerando os dados coletados, fica evidente a importância dos programas nos processos de exportação das MPEs gaúchas. Os diagnósticos, as consultorias, os incentivos e os acompanhamentos auxiliam significativamente os empresários a conhecerem novos mercados e oportunidades de expansão de suas empresas, pois as MPEs não possuem grandes estruturas para realizar todos estes processos. O Quadro 1 apresenta uma síntese dos programas e seus objetivos.

Durante o processo de coleta de dados, o Entrevistado 3 destacou ainda a Lei Kandir, a qual funciona como um incentivo fiscal por meio da isenção do imposto de ICMS para produtos e serviços destinados à exportação. Como não se trata de uma política, mas compreendendo a relevância do incentivo, optou-se por analisar o mesmo separadamente. Conforme o Entrevistado 3, os benefícios fiscais ajudam as empresas a aumentarem a sua produção e 
a redução de tributação incide diretamente na diminuição do preço final do produto. Os regimes de redução de impostos facilitam as operações de importação e exportação para as MPEs (APRENDENDO A EXPORTAR, 2018).

Quadro 1 - Síntese dos programas, promotores e seus objetivos

\begin{tabular}{|l|l|l|}
\hline \multicolumn{1}{|c|}{ Programa } & \multicolumn{1}{|c|}{ Promotor } & \multicolumn{1}{c|}{ Objetivo } \\
\hline Exporta-RS & $\begin{array}{l}\text { Secretaria do Desenvolvimento } \\
\text { Econômico, Ciência e Tecnologia do } \\
\text { estado do Rio Grande do Sul }\end{array}$ & $\begin{array}{l}\text { Fornecer informações sobre tendências } \\
\text { de mercado e exportadores. } \\
\text { Qualificar os agentes das empresas para } \\
\text { exportar. }\end{array}$ \\
\hline $\begin{array}{l}\text { Programa de Apoio } \\
\text { à Participação } \\
\text { de Empresas } \\
\text { Gaúchas em Feiras } \\
\text { Internacionais }\end{array}$ & $\begin{array}{l}\text { Secretaria do Desenvolvimento } \\
\text { Econômico, Ciência e Tecnologia do } \\
\text { estado do Rio Grande do Sul }\end{array}$ & $\begin{array}{l}\text { Identificar, custear e acompanhar as } \\
\text { empresas do Rio Grande do Sul na } \\
\text { participação de feiras internacionais. }\end{array}$ \\
\hline Peiex & $\begin{array}{l}\text { Apex Brasil } \\
\text { Governo Federal }\end{array}$ & $\begin{array}{l}\text { Promover a cultura exportadora. } \\
\text { Fornecer diagnósticos e capacitações. } \\
\text { Auxiliar na participação de rodadas de } \\
\text { negócios e feiras internacionais. }\end{array}$ \\
\hline Fundopem/RS & $\begin{array}{l}\text { Governo do Estado do Rio Grande } \\
\text { do Sul }\end{array}$ & $\begin{array}{l}\text { Incentivar as empresas a implantar ou } \\
\text { expandir suas unidades industriais, } \\
\text { financiando parte do ICMS. }\end{array}$ \\
\hline
\end{tabular}

Fonte: Elaborado pelos autores a partir dos dados coletados na pesquisa

Como o ICMS é um imposto cobrado pelos governos estaduais e parte da sua arrecadação é repassada aos municípios, quando o Governo Federal criou a Lei Kandir, estabeleceu-se um impasse. A decisão de incentivar as exportaçôes, mas isentando as empresas de pagarem um imposto estadual, gerou uma situação controversa. Para conseguir aprovação, o Governo Federal negociou uma compensação para os estados; a União repassaria anualmente o valor que foi deixado de arrecadar por causa da isenção.

A partir do ano de 2003 até 2006, o Governo Federal estipulou um teto de $\mathrm{R} \$ 3,9$ bilhões em repasses, mas, desde então, o valor não foi mais regulamentado, o causou divergências entre os Governos Estaduais e Federal. Os estados entendiam que a compensação deveria ser maior, e o Governo Federal alegava que sem a Lei Kandir a arrecadação de ICMS seria menor consequentemente. Como destaca o Entrevistado 3: "O Estado abriu mão dessa arrecadação no compromisso de que o Governo Federal repassaria, faria uma compensação disso e na prática o Governo Federal não está conseguindo fazer. (...) $\mathrm{O}$ impacto disso nas contas públicas dos Estados foi muito grande porque o Governo Federal não tem conseguido fazer os reembolsos”.

O ano de 2020 representou o fim desta situação com a homologação de acordo feito pela União, o Distrito Federal e os estados pelo Supremo Tribunal Federal. O acordo prevê o repasse de R \$ 65 bilhóes pela União entre 2020 
e 2037. Desta forma, haverá a compensação das perdas de arrecadação decorrentes da isenção do ICMS. Além disso, o acordo incluiu a ampliação da isenção que, desde 1988, era restrita a produtos industrializados, para todo tipo de mercadoria destinada à exportação (AGÊNCIA BRASIL, 2020; SUPREMO TRIBUNAL FEDERAL, 2020).

Após a apresentação dos programas e esta breve explanação sobre a Lei Kandir, é possível dar andamento ao estudo com a investigação das ações de qualificação de pessoas para a exportação.

\section{AÇÕES DE QUALIFICAÇÃO DE PESSOAS PARA A EXPORTAÇÃO}

Para Lopez e Gama (2011), a internacionalização estimula a eficiência das empresas e faz com que elas adquiram conhecimentos práticos que agregam vantagens competitivas em relação ao seu mercado de atuação. Mas, para exportar, é necessário ter conhecimento das etapas exigidas e quais são as melhores condiçóes de internacionalização (MINERVINI, 2012). Nesse sentido, é importante que os gestores das empresas tenham conhecimento em diversas áreas de gestão e internacionalização.

Programas como o Peiex oferecem assessorias individualizadas e capacitações (PEIEX, 2018). Os cursos ofertados pelo programa são direcionados às áreas de recursos humanos, finanças, tecnologia, comércio exterior, marketing internacional, entre outros diversos segmentos (ENTREVISTADO 3). O Peiex proporciona cursos de capacitação e assessorias para iniciar a internacionalização, como, por exemplo, auxílio na valorização e precificação dos produtos, ajudando no cálculo de valor de venda do produto em função das taxas aduaneiras e de câmbio, por exemplo (ENTREVISTADO 4).

O Entrevistado 1 declarou que, geralmente, os programas atuam com fomento à qualificação dos gestores das empresas com o intuito de que essas pessoas possam alcançar novos objetivos dentro das suas organizaçôes, seja para iniciar o processo de exportação ou melhorá-los. O Entrevistado ainda afirmou que, frequentemente, são promovidos seminários de qualificação e, a partir de um diagnóstico da maturidade e conhecimento da empresa e dos seus gestores, são definidos quais os cursos mais adequados.

De acordo com o Invest \& Export Brasil (2018), a assessoria realizada pelos projetos e programas auxilia com melhorias em diversas áreas da empresa, sendo que os progressos em conhecimento surgem a partir da participação em seminários sobre a cultura exportadora e participação em missóes internacionais. Nesse sentido, o gestor recebe um treinamento por parte das entidades que o auxilia na participação em feiras, assim ele é preparado para as demandas que serão exigidas no futuro (ENTREVISTADO 2). Além 
disso, os processos de qualificação têm como finalidade ensinar o gestor para que ele tenha uma independência maior dentro do contexto global de negócios (ENTREVISTADO 3).

Os entrevistados, quando questionados sobre quais são as ações voltadas à qualificação das pessoas, somente mencionaram alguns cursos propostos para melhorar ou aprimorar a gestão das empresas para o processo exportador. No entanto, é importante destacar as colocaçóes feitas pelo Entrevistado 5 ao afirmar que os gestores possuem outras necessidades, como as limitaçốes de conhecimento de idiomas estrangeiros. Esta limitação deixa os gestores desconfortáveis ao participarem de missóes internacionais. A barreira da língua é uma questão cultural que impede de se ter a inserção global. No entanto, como o aprimoramento oferecido pelos programas citados é direcionado a melhorias dentro das empresas para a inserção no mercado externo, é importante mencionar que esse tipo de qualificação relacionada com idiomas deve partir do próprio gestor. Para auxiliar no conhecimento de outros idiomas, o Governo Federal possui um programa chamado Idiomas sem Fronteiras (IsF). Esse programa é oferecido para estudantes de graduação e pós-graduação, técnicos e docentes de instituiçóes cadastradas pelo IsF e professores da educação básica. Há, também, uma plataforma on-line de cursos oferecidos pelo Governo Federal, a Escola do Trabalhador. Essa plataforma disponibiliza diversos cursos gratuitos, dentre eles, espanhol e inglês voltados ao mercado de trabalho.

De forma geral, as ações oferecidas pelos programas visam preparar o gestor para as principais áreas de gestão dentro da organização, sendo voltadas aos processos de internacionalização das empresas. O Quadro 2 apresenta uma síntese destas ações.

Quadro 2 - Síntese das ações de qualificação de pessoas oferecidas pelos programas

\begin{tabular}{|l|l|l|}
\hline \multicolumn{1}{|c|}{ Programa } & \multicolumn{1}{|c|}{ Promotor } & \multicolumn{1}{c|}{ Objetivo } \\
\hline Exporta-RS & $\begin{array}{l}\text { Secretaria do Desenvolvimento } \\
\text { Econômico, Ciência e Tecnologia do } \\
\text { estado do Rio Grande do Sul }\end{array}$ & $\begin{array}{l}\text { Promoção de seminários para } \\
\text { qualificação dos gestores para } \\
\text { internacionalização. }\end{array}$ \\
\hline $\begin{array}{l}\text { Programa de } \\
\text { Feiras-RS }\end{array}$ & $\begin{array}{l}\text { Secretaria do Desenvolvimento } \\
\text { Econômico, Ciência e Tecnologia do } \\
\text { estado do Rio Grande do Sul }\end{array}$ & $\begin{array}{l}\text { Treinamento para preparar o gestor } \\
\text { sobre o que ele precisa saber para } \\
\text { atender o importador na feira. }\end{array}$ \\
\hline Peiex & $\begin{array}{l}\text { Apex Brasil } \\
\text { Governo Federal }\end{array}$ & $\begin{array}{l}\text { Cursos de capacitação e assessorias para } \\
\text { internacionalização. }\end{array}$ \\
\hline Fundopem/RS & $\begin{array}{l}\text { Governo do Estado do Rio Grande } \\
\text { do Sul }\end{array}$ & Não possui \\
\hline
\end{tabular}

Fonte: Elaborado pelos autores a partir dos dados coletados na pesquisa 
O Quadro síntese, dentro da mesma lógica do anterior, permite a melhor visualização das informações coletadas e analisadas nesta pesquisa, servindo como apoio à próxima etapa, a qual compreende a investigação dos impactos d estas políticas nas atividades das MPEs.

\section{IMPACTOS PERCEBIDOS A PARTIR DAS POLİTICAS PÚBLICAS DIRECIONADAS À PROMOÇÃO DE EXPORTAÇÃO PELAS MPEs GAÜCHAS}

No Rio Grande do Sul, os núcleos operacionais do Peiex localizados nas cidades de Lajeado e Novo Hamburgo atenderam, juntos, 1500 empresas, entre 2008 e 2015. Em 2017, mais um núcleo foi instalado no estado, em parceria com a Fiergs, buscando atender empresas da Região Metropolitana de Porto Alegre e Serra (FEDERAÇÃO DAS INDÚSTRIAS DO ESTADO DO RIO GRANDE DO SUL, 2017). O Programa Exporta-RS, entre 2016 e 2019, prestou uma média de noventa consultorias para atender à demanda de busca de mercados ou alguma necessidade especial da empresa (ENTREVISTADO 1). Apesar do registro do número de empresas participantes, nenhum programa possui uma sistemática e acompanhamento e divulgação dos resultados.

Dada a limitação de dados quantitativos disponíveis para a análise dos impactos gerados por estas políticas e pela falta de mecanismos efetivos de controle dos resultados das mesmas, apenas uma análise qualitativa deste impacto pode ser realizada. Os atendimentos prestados pelos programas mencionados buscam implementar e fortalecer a cultura exportadora nas empresas. As assessorias proporcionam melhorias nas áreas de estratégia organizacional, vendas, marketing, entre outras, aumentando a competividade das empresas (INVEST \& EXPORT BRASIL, 2018). O Entrevistado 3 destaca a importância da competividade, colocando que, quando se desenvolve uma cultura de exportação nas empresas, diminui-se sua fragilidade, pois ela está trabalhando em outros mercados, preparando a empresa para atuar em cenários econômicos adversos.

Quando questionados, os entrevistados mencionaram impactos relacionados ao fortalecimento das empresas e à oportunidade de ampliar os mercados de atuação. O Entrevistado 1 cita que o Brasil sempre foi um país muito fechado para o exterior, fazendo com que, principalmente, as MPEs focassem no mercado local e ficassem fechadas para os mercados externos. O Entrevistado 5 menciona que o Brasil possui inúmeros produtos/recursos que proporcionam que as empresas sobrevivam internamente, o que leva a uma espécie de acomodação no mercado interno. O Entrevistado 3 destaca que o 
Brasil precisa ter um nível de maturidade maior, principalmente com relação a acordos comerciais. Para o entrevistado, o Brasil precisa fazer acordos comerciais com mais países, pois a falta de acordos dificulta a entrada das empresas em alguns mercados. Já o Entrevistado 5 menciona que os impactos gerados são pontuais e não sistêmicos, pois, para haver impactos sistêmicos, seria preciso alterar algumas questóes estruturais. Para o entrevistado, mesmo que tardiamente, o Brasil está conseguindo internacionalizar-se.

O Entrevistado 1 destaca ainda que não se trata de um processo rápido, mas os programas têm tido impactos interessantes. Para o entrevistado, as empresas aprovam os programas e, a medida que vão conhecendo as propostas, buscam cada vez mais participar das açốes sugeridas, pois o mercado local não é suficiente para o setor empresarial expandir e a busca por oportunidades em mercados fora do país têm sido alcançadas.

Para o Entrevistado 3, os impactos são uma maior estabilidade dentro da produção. Nesse caso, a cadeia produtiva é afetada, ou seja, se uma empresa começa a exportar ela aumenta a sua produção e, consequentemente, dos seus fornecedores. Outro ponto destacado pelo entrevistado é a diversificação de mercado. Além de aumentar a produção e a geração de empregos, o produto inserido no mercado externo traz visibilidade para o país. A questão de agregação de valor também foi citada pelo entrevistado, assim como a importância das empresas diversificarem os produtos para exportar.

O Entrevistado 2 citou que se as empresas estiverem preparadas para exportar, por meio de um bom planejamento e clara identificação de mercados, elas irão obter sucesso no processo de exportação. Os impactos positivos extrapolam aspectos puramente financeiros e benefícios como o aumento da motivação dos colaboradores são percebidos; a autoestima dos funcionários é elevada por reconhecerem que a empresa onde eles trabalham está exportando e o produto que ele ajuda a produzir vai ser consumido por alguém em outro país.

Os Entrevistados 1 e 3 mencionaram que, quanto mais MPEs exportarem, menos dependência se terá das exportaçôes das grandes empresas. Como as MPEs são a maior parte do total de empresas exportadoras, diluir as exportaçóes em um número maior de empresas diminui o risco de dependência de somente uma grande empresa na economia (ENTREVISTADO 1). Constata-se que as principais propostas dos programas envolvem ampliar e diversificar a base exportadora. Ampliar a base permite maior valor exportado, maior número de empresas exportando, maior variedade de produtos exportados, gerando, consequentemente, a conquista de novos mercados (ENTREVISTADO 3). 
O Quadro 3 apresenta a síntese dos impactos percebidos como consequência das políticas públicas de promoção à exportação na perspectiva dos entrevistados.

Quadro 3 - Síntese dos impactos percebidos pelos entrevistados

\begin{tabular}{|l|}
\hline Impactos percebidos \\
\hline Expansão do mercado de atuação. \\
\hline Impactos positivos financeiramente. \\
\hline Impactos positivos na autoestima dos funcionários. \\
\hline Estabilidade na produção \\
\hline Aumento da produção. \\
\hline Impactos na cadeia produtiva. \\
\hline Agregação de valor nos produtos. \\
\hline Melhores resultados econômicos para as regiões. \\
\hline Diminuição dos riscos de dependência das grandes empresas. \\
\hline Ampliação da base exportadora. \\
\hline Maior visibilidade para o país. \\
\hline
\end{tabular}

Fonte: Elaborado pelos autores a partir dos dados coletados na pesquisa

Após esta síntese dos impactos foi possível a compreensão das políticas ofertadas pelos atores públicos para a promoção das exportações pelas MPEs localizadas no Rio Grande do Sul, o que leva às consideraçôes finais.

\section{CONSIDERAÇÕES FINAIS}

A participação das empresas no comércio internacional, independente de seu tamanho, é uma decisão estratégica para o desenvolvimento do negócio. A base para uma empresa se internacionalizar é analisar a sua capacidade de exportação. Para as empresas de grande porte, geralmente, entrar no mercado externo é um processo mais fácil do que para as MPEs. Em alguns casos, a falta de uma estrutura maior, recursos financeiros ou conhecimento sobre exportação são fatores que dificultam a inserção das MPEs no mercado externo. Para auxiliar as MPEs na busca pela internacionalização, existem programas de apoio a exportação oferecidos pelos órgãos governamentais.

Neste estudo foram identificados programas de auxílio na inserção no mercado externo, a saber o Programa Exporta/RS, o Programa de Apoio à Participação de Empresas Gaúchas em Feiras Internacionais, ambos do estado do Rio Grande do Sul e o Programa de Qualificação para Exportação, o Peiex, de nível nacional.

Analisando o Exporta/RS foi possível identificar que o programa atua fortemente na busca por possíveis mercados de atuação para as MPEs. Os 
estudos realizados pelo programa detectam onde estão as demandas para determinados produtos e como as empresas podem se inserir no mercado identificado como potencial. Deste modo, o programa gera como benefício para a empresa a identificação de possíveis importadores. Isso é importante para as MPEs, porque é difícil, para aquelas que ainda não conhecem o mercado externo, identificar, dentro de inúmeras possibilidades, qual o melhor país para exportar e quais as condições exigidas nesta operação.

O Programa de Apoio à Participação de Empresas Gaúchas em Feiras Internacionais possui objetivo paralelo a um dos objetivos do Peiex: proporcionar às empresas a participação de feiras internacionais. É possível perceber que as feiras são oportunidades para os gestores apresentarem suas empresas e produtos ao mercado externo. Geralmente, nas feiras, é onde se consegue firmar parcerias para exportar.

O Peiex, além de promover a participação das empresas nas feiras e em rodadas de negócio, também busca identificar possíveis empresas exportadoras e promover a cultura de exportação nessas empresas. Percebe-se que as principais ações do programa visam demostrar ao gestor as oportunidades que o mercado externo apresenta, ao mesmo tempo em que apoia a estruturação das empresas para o processo de internacionalização.

As ações destes programas têm como objetivo auxiliar as MPEs a internacionalizar-se, mas, além disso, identificou-se que eles proporcionam qualificação para os gestores das empresas. As qualificaçôes são oferecidas por meio de assessorias, seminários de qualificação e cursos em diversas áreas de gestão empresarial. Percebe-se que os cursos são importantes para os gestores, pois agregam conhecimento para que a prática da exportação se torne mais fácil.

Com relação aos benefícios fiscais para promover as exportações tem-se o Fundopem/RS, programa de incentivo para empresas do estado do Rio Grande do Sul. O programa age como postergador de imposto (ICMS), sendo um incentivo para as empresas no momento de investir ou ampliar a área de produção.

Embora não seja um programa, foi destaca também a Lei Kandir, incentivo tributário oferecido pelo Governo Federal. A Lei indeniza as empresas pelo ICMS pago sobre produtos ou serviços destinados a exportação. Depois de um impasse de mais de duas décadas, em 2020 foi homologado pelo Supremo Tribunal Federal um acordo entre União, estados e o Distrito Federal para que ocorra o repasse dos recursos referentes às compensaçóes feitas pelos estados.

Como resultado das políticas públicas de exportação foi possível perceber que ocorreu uma mudança no modelo mental dos gestores e suas empresas. No passado, as empresas estavam voltadas às demandas do mercado interno, 
acreditando que empresas de pequeno porte não teriam capacidade de exportar. Esses conceitos foram alterados após as MPEs serem incentivadas a exportar, seja por necessidade, pelos programas que surgiram ao longo do tempo, ou por verem outras MPEs exportando e perceberem que também poderiam buscar o mercado externo.

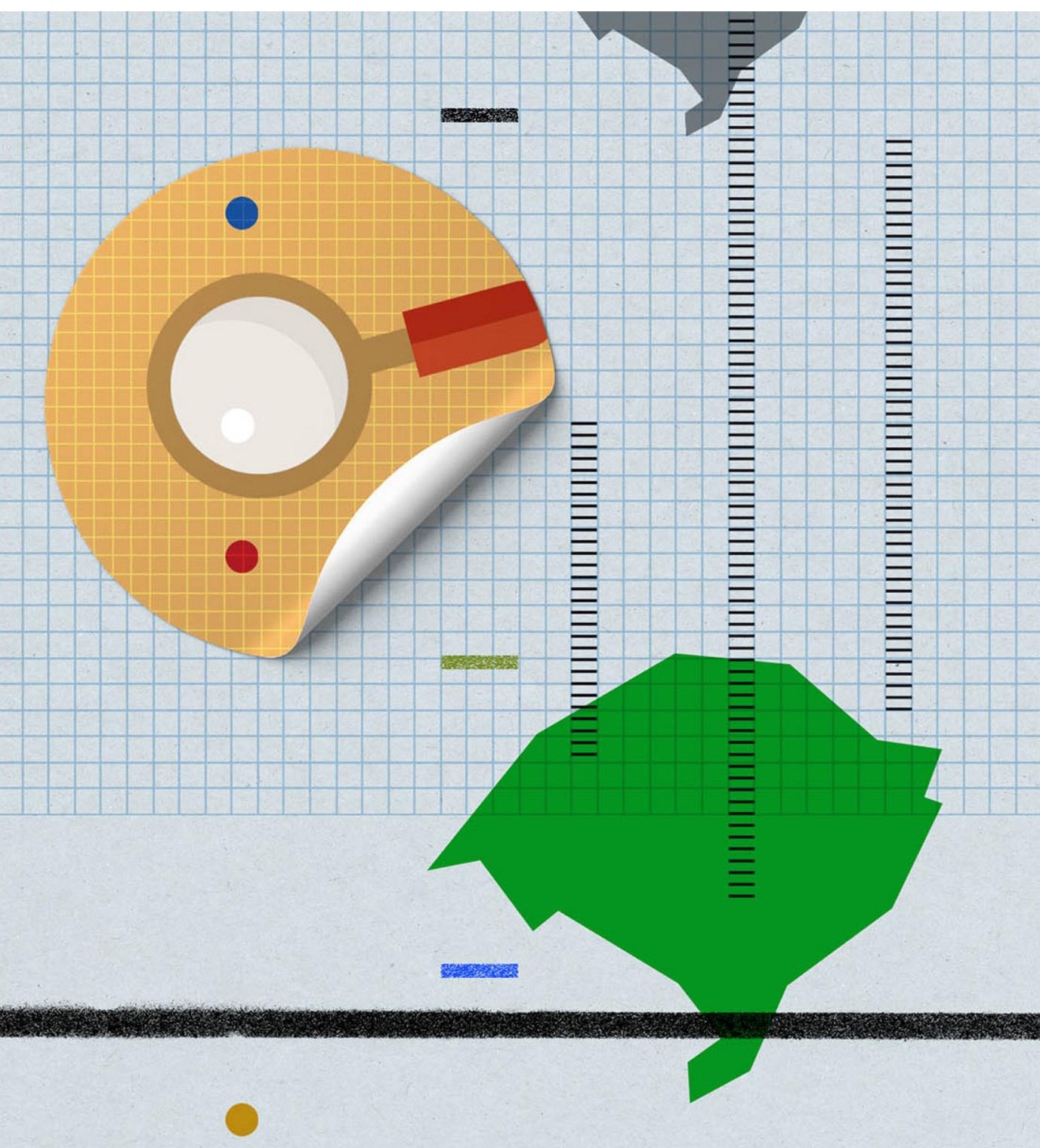


Ao realizar a pesquisa sobre os programas foi constatado que poucas informações estão disponíveis. As pesquisas na internet são limitadas, visto que nos sites, por exemplo, não há muitas informaçóes, dados ou divulgação dos objetivos e das ações dos programas. As entidades ou os governos responsáveis poderiam ampliar as informaçóes disponíveis, divulgando mais os programas, que assim poderiam atingir mais empresas.

Para as empresas é importante que elas introduzam rotinas de busca por novas oportunidades de mercado. As MPEs devem buscar conhecer os programas e incentivos destinados à exportação como uma maneira de diversificar e ampliar sua atuação. O processo de diagnóstico para identificar o potencial exportador de uma empresa, as consultorias e cursos oferecidos agregam inúmeros conhecimentos para as MPEs.

A maior limitação para o desenvolvimento deste estudo foi a limitação de informações referentes aos programas. Com relação aos programas a nível federal, embora haja a disponibilidade de informaçóes on-line sobre os mesmos, há limitação de dados sobre os resultados obtidos pelas empresas. Tratando-se de programas em funcionamento há mais de uma década, seria importante a apresentação de mais resultados quantificáveis que permitissem a análise dos reais resultados proporcionados por estes programas. No que tange aos programas ofertados pelo Rio Grande do Sul, mesmo sendo programas mais recentes, esta mesma limitação poderia ser superada com a divulgação de informações sobre os resultados obtidos pelas empresas participantes. Percebe-se que há uma carência de informaçôes sobre as políticas de apoio à exportação pelas MPEs no Rio Grande do Sul. Seria importante que estes programas fossem mais amplamente divulgados para que um maior número de empresas pudesse participar destas atividades, bem como para que a sociedade pudesse acompanhar os resultados gerados por estas iniciativas que são financiadas com recursos públicos.

Com relação ao desenvolvimento da pesquisa, cabe destacar uma limitação referente à análise da perspectiva das MPEs. Conforme destacado no método, inicialmente, não era objetivo do estudo investigar a percepção das MPEs. Entretanto, durante as entrevistas, observou-se esta necessidade. Apesar dos esforços, apenas o gestor de uma MPE foi entrevistado. Destaca-se aqui a necessidade de ampliação das pesquisas sobe o tema a partir da investigação desta perspectiva. Sugere-se a realização de estudos futuros com o emprego de diferentes abordagens metodológicas como entrevistas e levantamento do tipo survey. Uma pesquisa com esta abordagem permitirá efetivamente mensurar os impactos das políticas públicas com relação às exportações das PMEs gaúchas. 
Outra limitação importante que merece destaque é a falta de informações atualizadas sobre a internacionalização das MPEs. As bases de dados sobre exportaçóes vinculadas ao Governo Federal não permitem o recorte por porte das empresas. O último estudo publicado pelo Sebrae contendo informações sobre as exportações das MPEs data de 2017. Esta carência de informaçóes limita o desenvolvimento de estudos, mas não pode servir como restrição, ficando a demanda para novas publicações com este recorte.

\section{Referências}

AGÊNCIA BRASIL. União e estados chegam a acordo sobre perdas da Lei Kandir, 20 de maio de 2020. Disponível em: https://bit. ly/3l2NkcJ. Acesso em: 22 set. 2020.

APEX BRASIL - Agência Brasileira de Promoção de Exportações e Investimentos. 2018. Disponível em: https://bit.ly/3BNJVVi. Acesso em: 09 mai. 2018.

APRENDENDO A EXPORTAR. Sebrae, 2018. Disponivel em: https://bit.ly/3xagbOX. Acesso em: 11 nov. 2018.

APRENDENDO A EXPORTAR. Simples Exportação, 2018a. Disponivel em: https://bit. ly/373jVaf. Acesso em: 11 nov. 2018.

BUENO, J. R. Qual a receita bruta e o número de empregados para MEI, ME e EPP? Santa Catarina, 07 abr. 2017. Disponível em: https://bit.ly/2TEJvPT. Acesso em: 29 ago. 2018.

CONFEDERAÇÃO NACIONAL DO COMÉRCIO. As micro e pequenas empresas no Brasil. Rio de Janeiro, 2017. 56 p.

FACHIN, O. Fundamentos de metodologia. 5 ed. São Paulo: Saraiva, 2005. 209 p.

FEDERAÇÃO DAS INDÚSTRIAS DO ESTADO DO RIO GRANDE DO SUL. FIERGS e Apex-Brasil preparam empresas para exportação. Porto Alegre, 2017. Disponível em: https://bit.ly/2VdPv2y. Acesso em: 28 abr. 2019.

GIL, A. C. Como elaborar projetos de pesquisa. 4. ed. São Paulo: Atlas, 2002. 176 p.
GONDIM, A. Pequenos negócios já são mais de $40 \%$ das empresas exportadoras brasileiras. Diário Comércio Indústria e Serviços, Brasília, 21 dez. 2018. Disponível em: https:// bit.ly/2Vk4kkc. Acesso em: 28 abr. 2018.

INVEST \& EXPORT BRASIL - Guia de comércio exterior e investimento. Assessoria e diagnóstico para qualificar sua empresa, 2018. Disponível em: https://bit.ly/3zFSUpE. Acesso em: 11 nov. 2018.

LOPEZ, J. M. C. \& GAMA, M. Comércio Exterior Competitivo. 4. ed. São Paulo: Aduaneiras, 2010. $546 \mathrm{p}$.

MARCONI, M. A. \& LAKATOS, E. M. Fundamentos de metodologia científica. 7 ed. São Paulo: Atlas, 2010. 320 p.

MINISTÉRIO DA ECONOMIA. Crescem exportações de micro e pequenas empresas. Brasília, 25 set. 2017. Disponível em: https:// bit.ly/3yaAn4y. Acesso em: 29 ago. 2018.

MINERVINI, N. O exportador. 6. ed. São Paulo: Pearson Education Brasil, 2012. 364 p.

PRODANOV, C. C. \& FREITAS, E. C. Metodologia do Trabalho Científico: métodos e técnicas da pesquisa e do trabalho acadêmico. 2. ed. Novo Hamburgo: Feevale, 2013. 276 p. SEBRAE - Serviço Brasileiro de Apoio às Micro e Pequenas Empresas. Cresce exportação nas micro e pequenas empresas. O1 dez. 2017. Disponível em: https://bit. ly/373877M. Acesso em: 11 nov. 2018. 
SEBRAE. Exportação. 2018. Disponível em: https://bit.ly/3y8GGFJ. Acesso em: 11 nov. 2018.

SECRETARIA DO DESENVOLVIMENTO ECONOMICO E TURISMO. Exporta - RS. Rio Grande do Sul, 2019. Disponível em: https://bit.ly/3BOyQDd. Acesso em: 31 mar. 2019.
SECRETARIA DO DESENVOLVIMENTO ECONOMICO E TURISMO. Fundopem/RS e Integrar/RS. Rio Grande do Sul, 2019a. Disponível em: https://bit.ly/3rBFx7d. Acesso em: 31 mar. 2019.

SUPREMO TRIBUNAL FEDERAL. Plenário homologa acordo entre União e estados sobre compensações da Lei Kandir, 20 de maio de 2020. Disponível em: https://bit. ly/376ySbv. Acesso em: 22 set. 2020.

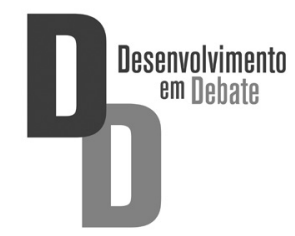

